\title{
A New Test Structure for the Electrical Measurement of the Width of Short Features with Arbitrarily Wide Voltage Taps
}

Richard A. Allen, Member, IEEE, Michael W. Cresswell, Member, IEEE, and Laurence M. Buck

\begin{abstract}
Accurate determination of the linewidth of a narrow conducting film for VLSI applications using electrical test structure metrology has required that the length of the line be many times its width to minimize geometric error due to the finite width of the voltage taps. However, long lines obscure important local effects such as nonuniformities in the film. Shorter lines highlight such effects. This paper describes a method of measuring the width of a short line having taps of arbitrary width. The effect of the taps is measured and used in the extraction of the linewidth allowing the determination of local linewidth variations with confidence.
\end{abstract}

\section{BACKGROUND}

$\mathrm{T}$ HE width of a line of a thin conducting material measured using a cross-bridge resistor [1]-[4] (Fig. 1) is given by

$$
W_{b}=\frac{R_{s} L_{b}}{R_{b}}
$$

where $R_{s}$ and $R_{b}$ are the sheet resistance and bridge resistance, respectively, and $L_{b}$ is the bridge length. However, (1) presumes zero-width voltage taps; the linewidth corrected for current shunting at the finite-width voltage taps is given by

$$
W_{b t}=\frac{W_{b}}{1-E}
$$

where the correction $E$ is given by [5]

$$
\begin{aligned}
E=\left(\frac{2 W_{b}}{\pi L_{b}}\right)\left[\left(\frac{D}{W_{b}}\right) \tan ^{-1}\left(\frac{D}{2 W_{b}}\right)\right. & \\
& \left.-\ln \left(1+\left(\frac{D}{2 W_{b}}\right)^{2}\right)\right]
\end{aligned}
$$

where $D$ is the width of the voltage taps. Since the only values available to calculate $E$ using (3) are the design values, it has long been recognized that $W_{b t}$ may be no closer to the actual linewidth than $W_{b}$ (i.e., the lines of the test structure almost certainly will not be fabricated with exact width, placement, and perfect $90^{\circ}$ corners). Thus, (3)

Manuscript received February 18, 1992. This work was supported in part by the DARPA X-Ray Lithography Program.

The authors are with the Semiconductor Electronics Division, National Institute of Standards and Technology, Gaithersburg, MD 20899. IEEE Log Number 9200806 has been used to develop design guidelines which minimize $E$ so the actual correction is negligible for features fabricated within a given tolerance. However, these guidelines introduce the potentially undesirable constraints that $L_{b} \gg W_{b}$ and $W_{b} \geq D$ [1], [3], [4]. The method described in the present work shows how these constraints may be removed allowing the measurement of the width of short bridges using a new test structure design and measurement procedure.

\section{Principal Features of the New Linewidth Test STRUCTURE}

The proposed new linewidth test structure (Fig. 2) consists of a van der Pauw cross and three bridge resistors. This test structure embodies the salient features of the structures used in the proof-of-concept experiment described later in this paper. The bridge of length $L$ replaces the conventional (long) bridge. The two bridges of length $L_{l}$ are used to measure the effect of finite-width voltage taps on the electrical length of the bridge resistor by using voltage taps not connected to pads ("dummy" taps) to emulate the effect of active voltage taps [6]. All voltage taps cross the current-carrying line and are tapped from a single side to minimize the uncertainty introduced by asymmetric corner rounding [7]. Since the geometric error is measured and used to correct the extracted linewidth, there are no suggested design rules for the width and length of the bridge or the width of the taps other than those required by the process. Otherwise, the new test structure conforms to established rules for cross-bridge resistor design [2].

\section{Linewidth Extraction Procedure}

Sheet resistance is extracted from the van der Pauw cross as described in [1]-[4]. Then, a fixed current $I_{b}$ is forced between pads 4 and 1 as the voltages $V_{56}, V_{67}$, and $V_{78}$ are recorded. The current is reversed and the voltages again are measured, and the magnitudes are averaged. The change in the electrical length, $\delta L$, of a segment of line due to a single tap is

$$
\delta L=L 1\left(\frac{V_{56}-V_{67}}{n V_{56}+\left(V_{56}-V_{67}\right)}\right)
$$




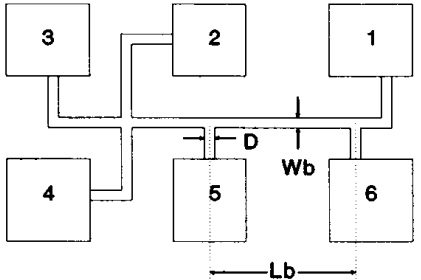

Fig. 1. The basic cross-bridge resistor test structure.

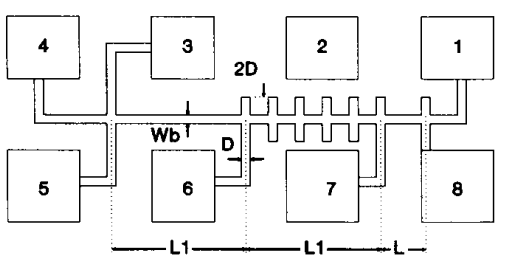

Fig. 2. Proposed short bridge resistor test structure.

where $n$ is the number of "dummy" taps. For the bridge segment between taps 7 and 8 the electrical length is $L_{e}=$ $L_{b}-\delta L$. Thus, the width of the line segment with $R_{b}=$ $V_{78} / I_{b}$ is

$$
W_{b}=\frac{R_{s} L_{e}}{R_{b}} .
$$

\section{Example of Application and Measurement RESULTS}

The validation of the design shown in Fig. 2 is based on results obtained using Kelvin-tapped, bridge resistor test structures and nearby van der Pauw crosses. The structures were fabricated in chrome on quartz using an optical stepper reticle. The bridge widths (design) were 1 and $2 \mu \mathrm{m}$ and the lengths 12 and $165 \mu \mathrm{m}$. Measurements were made at four sites near the center of the mask. The extracted sheet resistance was $18.60 \pm 0.13 \Omega / \square$. The $\delta L$ values, the "ideal" geometric errors from (3), and the uncorrected and corrected linewidths of representative bridges are listed in Table I.

To highlight the importance of using the subject technique, the systematic errors of the linewidths of the $12-\mu \mathrm{m}$ bridge, expressed as a percent difference from those of the adjacent $165-\mu \mathrm{m}$ bridge, were calculated and are shown in Table II. As expected, the data show that evaluating the linewidth using (1) for the $12-\mu \mathrm{m}$-long bridge significantly overestimates the actual linewidth. However, through use of the $\delta L$ method embodied in (5) these errors are essentially eliminated, with the remaining differences less than $1 \%$ of the width. Further, since the average error for the corrected linewidths is within one standard deviation of zero, it is possible that there is no significant systematic error remaining in the measurement.

To evaluate the source of the remaining differences, optical linewidth measurements of the 12- and $165-\mu$ m-long bridges at a single mask site were made using the NIST Automated Linewidth Measurement System [8]. These measurements revealed linewidth variations of up to $0.04 \mu \mathrm{m}$ within a
TABLE I

Representative Values of $W_{b}$, Calculated Using (1) and the $\delta L$-CORRECTED (5), FOR $L=165 \mu \mathrm{m}$ AND $L=12 \mu \mathrm{m}$. Also Shown is the Measured Value of $\delta L$ for Each Test Site.

\begin{tabular}{|c|c|c|c|c|c|}
\hline \multirow{3}{*}{$\begin{array}{c}\text { As-Drawn } \\
W_{b}, D \\
(\mu \mathrm{m})\end{array}$} & \multirow{3}{*}{$\begin{array}{c}\delta L \\
\text { Measured } \\
(\mu \mathrm{m})\end{array}$} & \multicolumn{4}{|c|}{ Linewidth, $W_{b}$} \\
\hline & & \multicolumn{2}{|c|}{ (for $L=165 \mu \mathrm{m}$ ) } & \multicolumn{2}{|c|}{$($ for $L=12 \mu \mathrm{m})$} \\
\hline & & $\begin{array}{c}(1) \\
(\mu \mathrm{m})\end{array}$ & $\begin{array}{c}(5) \\
(\mu \mathrm{m})\end{array}$ & $\begin{array}{c}(1) \\
(\mu \mathrm{m})\end{array}$ & $\begin{array}{c}(5) \\
(\mu \mathrm{m})\end{array}$ \\
\hline \multirow[t]{4}{*}{1,1} & 0.64 & 1.102 & 1.097 & 1.143 & 1.088 \\
\hline & 0.65 & 1.103 & 1.099 & 1.147 & 1.089 \\
\hline & 0.77 & 1.089 & 1.084 & 1.147 & 1.079 \\
\hline & 0.54 & 1.133 & 1.130 & 1.175 & 1.137 \\
\hline \multirow[t]{4}{*}{2,2} & 0.64 & 2.056 & 2.048 & 2.151 & 2.042 \\
\hline & 0.61 & 2.048 & 2.040 & 2.144 & 2.041 \\
\hline & 0.69 & 2.041 & 2.033 & 2.140 & 2.026 \\
\hline & 0.67 & 2.049 & 2.041 & 2.158 & 2.048 \\
\hline
\end{tabular}

TABLE II

Percent Difference of the Width of the $12-\mu \mathrm{m}$-Long Bridge FROM THAT OF THE AdJACENT 165- $\mu$ m-Long BRIDge as EXPECTED From (3) and as Measured USing (1) and (5) at Four Sites

\begin{tabular}{|c|c|c|c|}
\hline $\begin{array}{c}\text { As-Drawn } \\
W, D \\
(\mu \mathrm{m})\end{array}$ & $\begin{array}{c}\text { Expected } \\
(1) \\
(\%)\end{array}$ & $\begin{array}{l}\text { Uncorrected } \\
\begin{array}{c}(1) \\
(\%)\end{array}\end{array}$ & $\begin{array}{c}\delta L \text { Correction } \\
\text { Applied (5) } \\
(\%)\end{array}$ \\
\hline 1,1 & $\begin{array}{l}-1.2 \\
-1.2 \\
-1.2 \\
-1.2\end{array}$ & $\begin{array}{l}-4.4 \\
-4.3 \\
-5.7 \\
-5.0\end{array}$ & $\begin{array}{r}0.9 \\
0.9 \\
0.5 \\
-0.6\end{array}$ \\
\hline 2,2 & $\begin{array}{l}-2.4 \\
-2.4 \\
-2.4 \\
-2.4\end{array}$ & $\begin{array}{l}-4.9 \\
-5.0 \\
-5.4 \\
-5.8\end{array}$ & $\begin{array}{r}0.3 \\
-0.0 \\
0.3 \\
-0.3\end{array}$ \\
\hline
\end{tabular}

Average error after correction: $0.2 \pm 0.5$

single structure. This suggests that these differences between the measured widths of the 12- and $165-\mu \mathrm{m}$-long lines calculated using (5) are due to physical variations in the widths of the lines rather than artifacts introduced by the measurement technique.

\section{Conclusions}

A powerful new method for measuring the linewidth of a single short line with arbitrary width voltage taps has been developed. This method allows the determination of the local nonuniformity of lines having lengths of the order of the gate widths of MOS transistors used in VLSI.

\section{ACKNOWLEDGMENT}

The authors acknowledge the valued contributions of $\mathrm{C}$. Ellenwood of NIST for digitizing the design of the test structure, of C. Vezzetti of NIST for providing the optical measurements, of R. Mattis and R. Larrabee of NIST for numerous helpful comments, of J. Walters and J. Gonzalez of NIST for their editorial support in preparing the manuscript, and the staff of Photronix Corporation for recommendations and technical inputs in the preparation of the patterned chrome plates.

\section{REFERENCES}

[1] M. G. Buehler, S. D. Grant, and W. R. Thurber, "Bridge and van der Pauw sheet resistors for characterizing the line width of conducting layers," J. Electrochem. Soc., vol. 125, pp. 650-654, 1978.

[2] M. G. Buehler and C. W. Hershey, "The split-cross-bridge resistor 
for measuring the sheet resistance, linewidth, and line spacing of conducting layers," IEEE Trans. Electron Devices, vol. ED-33, pp. $1572-1579,1986$

[3] P. Troccolo, L. Mantales, R. Allen, and L. Linholm, "Extending electrical measurements to the $0.5 \mu \mathrm{m}$ regime," in Proc. I99I SPIE Symp. Integrated Circuit Metrology, Inspection, and Process Control V, vol. 1464, 1991, pp. 90-103.

[4] H. A. Schafft, "Standard test method for determining the average width and cross-sectional area of a straight, thin-film, metal line,' ASTM Committee F-1, Doc. 20914Z, to be published.

[5] P. M. Hall, "Resistance calculations for thin film patterns," Thin Solid Films, vol. 1, pp. 227-295, 1967-1968.
[6] M. W. Cresswell, M. Gaitan, R. A. Allen, and L. W. Linholm, "A modified sliding wire potentiometer test structure for mapping nanometer-level distances," in Proc. 1991 Int. Conf. Microelectron. Test Structures, Mar. 1991, pp. 129-134.

17] R. A. Allen and M. W. Cresswell, "Elimination of effects due to patterning imperfections in electrical test structures for submicrometer feature metrology," Solid-State Electron., vol. 35, no. 3, pp $435-442,1992$

[8] J. E. Potzick. "Automated calibration of optical photomask linewidth standards at the National Institute of Standards and Technology," in Proc. 1989 SPIE Symp. Microlithography (San Jose, CA), vol. 1087-34, pp. $165-178$. 